Stenford Matenda

Centre For Learning and

Teaching Development,

Walter Sisulu University,

Mthatha, South Africa

Email: smatenda@wsu.ac.za

(corresponding author)

ORCID: https://orcid.

org/0000-0003-2753-5585

Dr Gedalla Mulliah

Naidoo

Department of

Communication Science,

Faculty of Arts, University

of Zululand Kwadlangezwa,

South Africa

Email: NaidooG@unizulu.

ac.za (corresponding author)

ORCID: https://orcid.

org/0000-0001-5445-0160

Prof. Hemduth Rugbeer

Department of

Communication Science,

Faculty of Arts, University of

Zululand, Kwadlangezwa,

South Africa

Email: vijayrugbeer@gmail.

com

ORCID: https://orcid.

org/0000-0001-5588-4964

DOl: https://dx.doi.

org/10.18820/24150525/

Comm.v25.10

ISSN 2415-0525 (Online)

Communitas 2020 25: 1-15

Date submitted:

21 July 2020

Date accepted:

04 September 2020

Date published:

29 December 2020

(c) Creative Commons With Attribution (CC-BY)

open Access

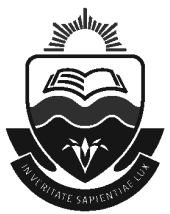

\section{A STUDY OF YOUNG PEOPLE'S \\ USE OF SOCIAL MEDIA FOR \\ SOCIAL CAPITAL IN MTHATHA, \\ EASTERN CAPE}

\section{ABSTRACT}

The concept of social capital is gaining popularity in a context where young people are facing increasing social and economic challenges. In the same vein, social media use by this group has become pervasive. This study seeks to understand whether these social technologies now provide new opportunities for the youth in semi-rural areas to access social capital, especially since social capital is a necessity for personal and social development. A mixedmethods research design was used in this study with 331 questionnaires distributed to students in high schools and two tertiary institutions in Mthatha in South Africa's Eastern Cape province. Focus groups were conducted with the same target group. The results show that social media tools are embedded in the everyday lives of young people and that these tools are an important source of social capital. They are not being used only for dating and play, but for other everyday tasks such as learning and helping others, and are a source of personal benefits. The study concludes that social media applications are an important resource for social capital and that it is important to make policy reconsiderations to ensure inclusive youth development.

Keywords: social media; social capital; youth; horizontal communication; online communication

\section{INTRODUCTION AND BACKGROUND}

Many African countries face challenges related to poverty and unemployment, but the worst-hit population group in these countries, including South Africa, are young people below the age of 35. In the Vulnerable Groups Report in 2017, Statistics South Africa reported that young people in this age group constituted 36.9 percent of the total population. The Report further pointed out that 62.7 percent of young people are unemployed and another 1.9 million are on social grants. As pointed out by Diof (2003), they are indeed the most affected and vulnerable social group. 
There is general acknowledgement that young people must be integrated into society as this empowers them to contribute meaningfully to the development of society (Ahmad \& Sheikh 2013). The Integrated Youth Development Strategy, developed by the National Youth Development Agency, states that integrating this group is the only way South African society can achieve cohesiveness, sustainability and democracy. For young people, inclusiveness is essential as it is a tool for promoting a sense of citizenship. As argued by De Zúñiga and Valenzuela (2011) and Bennet and Sergeberg (2011), youth engagement is vital because it provides opportunities for young people to grow their sense of citizenship; thereby, improving participation. This participation boosts democracy and the observance of human rights. Participation in the civic, political and economic spheres of governance is also important as it develops a sense of collective efficacy; a deep acknowledgement that one needs to work with others to overcome some of the challenges that face present-day societies. Collective efficacy arises from a recognition that all investments in social relations often result in returns to the individual or the group as a whole (Munzel et al. 2008). This has been termed social capital, which refers to how one's social connections can be used to access resources that are important to one's well-being (Bourdieu 1985).

Given the pervasiveness of social media tools, questions have arisen as to how the resultant social connectivity enables the young generation to acquire social capital. It has become imperative to understand whether the usage of these digital technologies has enhanced the acquisition of social capital. Several scholars (Bennet 2008; Van Deth 2009; Theocharis 2015; Boulienne 2015; Papacharissi 2008) have concluded that platforms such as Facebook, Twitter, Linkedln, and YouTube have widened and deepened civic participation by young people. Given that civic participation involves working with others to address social issues, that participation is a powerful source of social capital. This article examines whether young people in Mthatha in South Africa's Eastern Cape province are deriving any social capital from the usage of such digital tools.

\section{SOCIAL CAPITAL}

The concept of social capital rose to prominence towards the turn of the twentieth century and was appropriated by different social science disciplines, including sociology, psychology, communication science, and politics (Putnam 2002). Many scholars agree that social capital is essential for any society's development. However, what has remained debatable is the efficacy of the concept, which led other scholars like Lin (1999: 28) to question whether the concept is just a fad without enduring qualities that can underpin intellectual efforts to understand the importance of cooperating with others.

While the concept has been defined differently by different scholars, there is mostly consensus among scholars that it involves an individual's use of social networks to gain access to and use resources, either for personal or community benefit. Liu et al. (2016) observe that the need to belong is a human trait and that this need is important for reproduction and the survival of individuals. To overcome problems, human beings co-operate with others to share resources that are required for the 
attainment of mutually beneficial relationships. The underlying theme of this concept is that interacting with others, in as much as it is as old as humanity itself, is important for any human being to achieve personal and social goals. Portes (1998) points out that connecting with others has become so important because it is the only way to prevent anomie, as well as self-destruction. Some key and pioneering scholars on the social concept (Bourdieu 1985; Burt 1992; Adler \& Kwon 2002) agree that social relations are essential, as they are a source of other important resources. These scholars' definition of the concept highlights the value of social connections, be they ordinary friendships or normal contact with colleagues and neighbours. This value in social connections could be changed to other types of capital, which could be mere favours or simply information that is essential for one to access economic capital (Portes 1998; Lin 1999). However, for these connections to have value, relationships must be maintained and serviced. If they are not in a satisfactory state, then one will not derive any value from them. Munzel et al. (2014) further observe that human nature is defined by the notion of reciprocity, which maintains that certain actions are contingent on our expectations for rewards from others. Hence, whenever people give something to others, they expect something in return, which implies that all relations with others are usually guided by the norm of reciprocity. In simple terms, Lin (1999) stated that having many social relations that one can activate when one needs help is not different from having large sums of money in different banks that one can access every time one needs help.

Norris (2003) identifies civic spaces of collaboration in society as important sites for social capital accumulation and points out how such connections are invaluable for the production of goods and services. Such relationships are governed through norms and tacit rules, which in turn define the obligations and responsibilities of those connected. With these norms, understandings and rules, people can easily work together for the betterment of their lives and society in general (Julien 2015). Ferreira and Pantidi (2018) introduced the concept of community resilience, stating that this can only be attained when people self-organise and use available resources to creatively help each other to adapt and be resourceful to achieve individual as well as community well-being.

When people act in a common interest to achieve set objectives, they acquire social capital, which is both an outcome and a precursor to collective action (Mandarano et al. 2011). Through community togetherness, which Julien (2015) calls communitarianism, community members can participate in both private and public spheres of life, which include churches, workplaces, places of residence and public gathering spaces. These affiliations and associations are important for individuals to gain access to resources, which are essential for everyday living. As Portes (1998) argued, the solidarity that emerges amongst people is important for generating a sense of belonging. Furthermore, as asserted by Mandarano et al. (2011), social capital "facilitates sharing of information, sharing to arrive at mutual understanding, leading to conflict resolution, more decision making, more efficient co-ordination, and increased capacity to respond to future challenges enables the creation of new relationships". 
The nature of social capital derived from social networks is dependent on network size, relationship strength, and the nature of the resources that are available in the network (Ellison et al. 2014a; Ellison et al. 2014b; Lin 1999). Hence, people who have a bigger network, stronger ties and better-resourced networks are more likely to have more social capital, which in turn affects the level of success personally, and even as a community.

Putnam (2002) distinguishes between bridging and bonding social capital. Bonding social capital is the type of social capital that happens between people who are like one another in the most important respects, while bridging social capital occurs between those that are fundamentally different in social characteristics (ibid.). Even in similar groups, bridging connections exist, which is called internal bridging, while connections could exist between groups, which is referred to as external bridging. In this distinction, Greys and Mudock (2010) emphasise that groups must be seen as merely a set of individuals who may have come together voluntarily or involuntarily. This means that when people form groups, whether for a specific aim or not, they constitute a group and in that group connections emerge inside and with other groups. This serves an important social function because trust, norms and values develop. This is the social capital that will become invaluable to members of groups.

\section{Social capital and young people}

As pointed out by Boeck (2011), literature on the social capital of the youth as a social group remains scant. This generally creates a gap wherein measures that have been used to assess social capital amongst adults and communities are applied to this age group, which might render their social capital invisible. This is problematic given that in the face of new technologies and problems, such as unemployment, political apathy and social development challenges, which this group face, researchers are unable to see how they are adapting their lives to these new conditions. Leonard (2008) writes that "[t]heir own ability to develop stocks of social capital is underplayed. What these approaches have in common is a tendency to see young people as human becomings rather than human beings." This points to the hazards of overlooking the nature and types of relationships that the youth develop and can harness in their everyday lives. Chawla and Malone (2002) state that the greatest weakness of the few available studies is that they focus on how young people access and generate social capital, which means that the thrust is on social justice and inclusion in a society dominated by the old.

The inclusion of the youth in nation-building is a priority of many governments; hence, the importance of understanding how the youth's connections between themselves and the community generate social capital. In other words, it is imperative to understand how the youth develop, shape and are shared by the networks, which are by and large made and strengthened in the digital realm.

\section{Social media and social capital}

The pervasiveness of social media has implications for all facets of social life and how people have become social (Castells 2005). With hundreds of millions of young 
people connected through several popular social media platforms, it means these technologies provide new ways of connecting them as friends, neighbours, colleagues, and citizens. Such ties, as argued by Norris (2003), allow young people to collaborate, co-ordinate and co-operate to produce social capital. The ubiquity of these social networks has generated an abundance of research as people seek to understand how these technologies are being exploited for generating social capital. Norris (2003:1) asked the same question that researchers are grappling with today, namely "[c]an online communities become substitutes for traditional forms of collegiality and social interaction based on traditional face to face contact in families, firms and local communities ... can trust be engendered online, in the absence of all the usual contextual cues derived from social relationships?".

Several studies have been undertaken to ascertain whether social media platforms have enabled people to acquire more social capital (Ellison et al. 2014b; Liu et al. 2016; Ha et al. 2016). Most of these studies have concluded that there is a positive correlation between social media use and social capital acquisition. As pointed out earlier, connecting with others is now cheaper, decentralised and faster, and participation in those groups easier; something that has made social capital generation much easier (Mandarano et al. 2017). These social technologies have facilitated resource mobilisation and relationship maintenance and creation. Julien (2015: 358) writes that digital technologies make it easier for people to acquire social capital, but decries that there is not much research into "how interactions of digital inhabitants, who invest themselves online and subsequently have a stock of capital that exists and is exchanged online, have been overlooked and misunderstood".

Since information is one of the key resources of social media, it is commonly agreed that in a networked society information has become abundant and sharing knowledge has become easier, which make it much easier for people to work with others to generate mutually beneficial goods and services. Apart from information access, Liu et al. (2016) also state that social media usage has enabled self-disclosure, relationship maintenance and grooming, and online friendship initiation. Writing about Facebook, Ellison et al. (2014a) assert that the platform has opened new channels of communicating in a meaningful way, and that even where relationships already existed, these social ties have been strengthened. Thus, social media platforms can assist in making weak ties stronger.

Presti (2014) introduces the capability approach to the study of social capital and points out that social networks have enhanced people's capabilities, which enable them to achieve and exercise well-being. The argument which is proffered by Presti (2014) is that even if capital is available, be it relational or economic, there are sets of capabilities required for their effective exploitation. Therefore, social media platforms have specific affordances that enable people to generate and exploit social capital to achieve specific objectives. Several studies on the use of social media platforms (Ellison et al. 2014a; Ellison et al. 2014b; Zhang \& Lin 2018) found that social capital enhancing activities, such as consuming news, discussions and user-generated content, have made collective action and social capital accumulation much easier. Generally, social media platforms generate weak ties, which are often disparate; for 
this reason, they are important in helping users to acquire bridging social capital. Liu et al. (2016) also state that gender and other cultural differences impact on the social capital generated from social networks. Women obtain more social capital from these platforms because they tend to have more "friends"/connections than their male counterparts. Besides, Western cultures tend to generate more bridging social capital, while collectivist societies in Asia and Africa are more likely to promote bonding social capital. In another study, Phua et al. (2017) compared the various social media platforms and their ability to generate bridging social capital and concluded that Twitter was most important, followed by Instagram, Facebook and Snapchat. However, Snapchat was the highest where bonding social capital was considered.

\section{RESEARCH DESIGN}

This study used a mixed-methods research design. This design was used as it provides important insights on the uses, reasons and perceptions of research participants (Cresswell \& Cresswell 2018). Since the design is underpinned by pragmatism, it enables the creative use of methods, the synthesis of theories, and research outcomes. To obtain quantifiable results that enable generalisation, a quantitative survey was conducted. This entailed the distribution of self-administered questionnaires to 174 high school students, while another 173 were distributed to students at Walter Sisulu University and KSD TVET College, the two public tertiary institutions in Mthatha. The participants were selected using the multi-stage cluster sampling procedure.

Qualitative data was gathered using focus group discussions. Six focus groups were conducted: two from selected schools, two from KSD TVET, and two from Walter Sisulu University. The participants were selected using the convenience sampling technique. Each focus group was an hour long (on average), and the groups included between six and eight participants. Participation was voluntary and confidentiality wasguaranteed.

\section{RESULTS AND ANALYSIS}

The primary reasons why young people use social media, according to the study, is that these platforms allow them to grow their networks so that they can gain social capital. This capital is important for community empowerment or to provide access to individual opportunities for personal development; it is usually generated in the course of self-activity. The study also sought to understand how civic engagement enacted through social media could bring about personal and community benefits. The findings indicated that young people used social media to grow these social networks so that they could address the personal and social needs they encountered. Social groups and individuals are appropriating social media to acquire social capital, and civic life is the vehicle through which social capital is acquired. Moreover, young people work with each other to assist one another to achieve their own "community" aims.

\section{Social media, education and social capital}

Universities and high schools are communities in their own right, and these communities' need to co-exist and support each other is immense. As argued by Liu et al. 
(2016), survival in such institutions is also dependent on the networks that one can create. Research has been undertaken to understand the role of social media platforms in learning, and since co-operation between members of the same community is essential, it is essential to show how social ties help in learning. The participants in this study maintained that social networks have communities within the social media spaces; thus, enabling members to foster a sense of mutual concern. One of the participants from a tertiary institution commented as follows:

The people I interact with are the most important people in my life. They are my community. I rarely go to my rural home anymore - that place is no longer important. When we belong to groups, I feel like it's more real. If one of us has a problem, we try to find ways of assisting. Without these groups, I will be very lonely.

Other participants added that to them, their home neighbourhoods now play a less significant role in their lives. One of the participants from a high school said:

My classmates, teachers and a few of my friends are now my community. You see, I spend most of my time here. I come here even on Saturday and we are studying on Sundays. My home now is just a place to go and sleep. That is life. And these are the people I keep in touch with and I do not see myself playing an active role at home. From here, I will go to university and that's it.

This means that the theatre of understanding social capital accumulation is now the spaces of tertiary institutions and high schools. Social connectivity in these spaces then becomes social capital, since it adds value to one's life while at these learning spaces. This makes social networks indispensable tools for learning. When asked about the value of communicating with other learners, the respondents in this study responded as follows: $38.53 \%$ agreed; $35.78 \%$ strongly agreed; $2.45 \%$ strongly disagreed; $8.26 \%$ disagreed; and $14.98 \%$ were neutral. It means that $74.31 \%$ of the respondents believe that social media applications are valuable for academic purposes. As argued by Liu et al. (2016) and Ellison et al. (2014a), social media platforms are important because they allow for resource mobilisation, self-discourse, information access, relationship repair, building and initiation among others. In the educational setting, interactions amongst students, and also with lecturers and university administrators are important for the success of learning. Social networks enable regular and cheaper communication (Ellison 2014a).

These sentiments were echoed by results from the focus groups where a participant highlighted the following:

One cannot afford not to be on social media. I have to be on WhatsApp as that is where we get information about classes, tests and announcements mainly because it is cheaper. We also share tips or even resources there.

Another participant added that as they add their statuses and pictures (self-disclosure) on applications, such as Instagram and Facebook, they acquire new acquaintances at their institutions, as well as strengthen existing relationships (Ha et al. 2016). One of the participants stated that: 
When we arrived here we barely knew each other. As time went on, we started sharing information and later by following each other on social networks, I think I now know most of my classmates and I would agree that this relationship has been strengthened by social networks especially WhatsApp, Facebook and Instagram.

However, unlike the findings by Phua et al. (2017) and Ellison et al. (2014a), who concluded that social networks mostly help for the cultivation of bridging social capital, this study revealed that initially it is bridging social capital that is generated, but as cohesion in an educational setting improves and identities coalesce, it is mostly bonding social capital that predominates such contexts. Social networks are vital in enhancing cohesion and the development of collective identities in educational spaces, which facilitates the cultivation of bonding social capital.

\section{Social media, information access and social capital}

One of the most important developments brought about by social networks has been that they have made information abundant, easily accessible, cheap, and available in different formats (Boyd \& Ellison 2007; Fuchs 2015). Unlike in the past when information provision was dominated by corporations, now users are also able to generate, disseminate and curate information. This decentralised communication system means that users can communicate horizontally without the influence of political and economic elites (Fuchs 2016; Kaplan \& Heinlein 2012; Steenkamp \& Hyde-Clarke 2012). Information availability is an important resource for transforming social capital into other forms of capital, such as favours and money. This study confirmed that social capital was important for various reasons, especially for this targeted group, namely that they can hear about opportunities, such as bursaries, jobs and voluntary work opportunities, and even other forms of assistance.

As the population under study is from a poverty-stricken area, concerns over higher education funding are ever-present. The ability to access funding opportunities is therefore important to this target group. Figure 1 shows that most participants use social media to gain access to funding opportunities. 


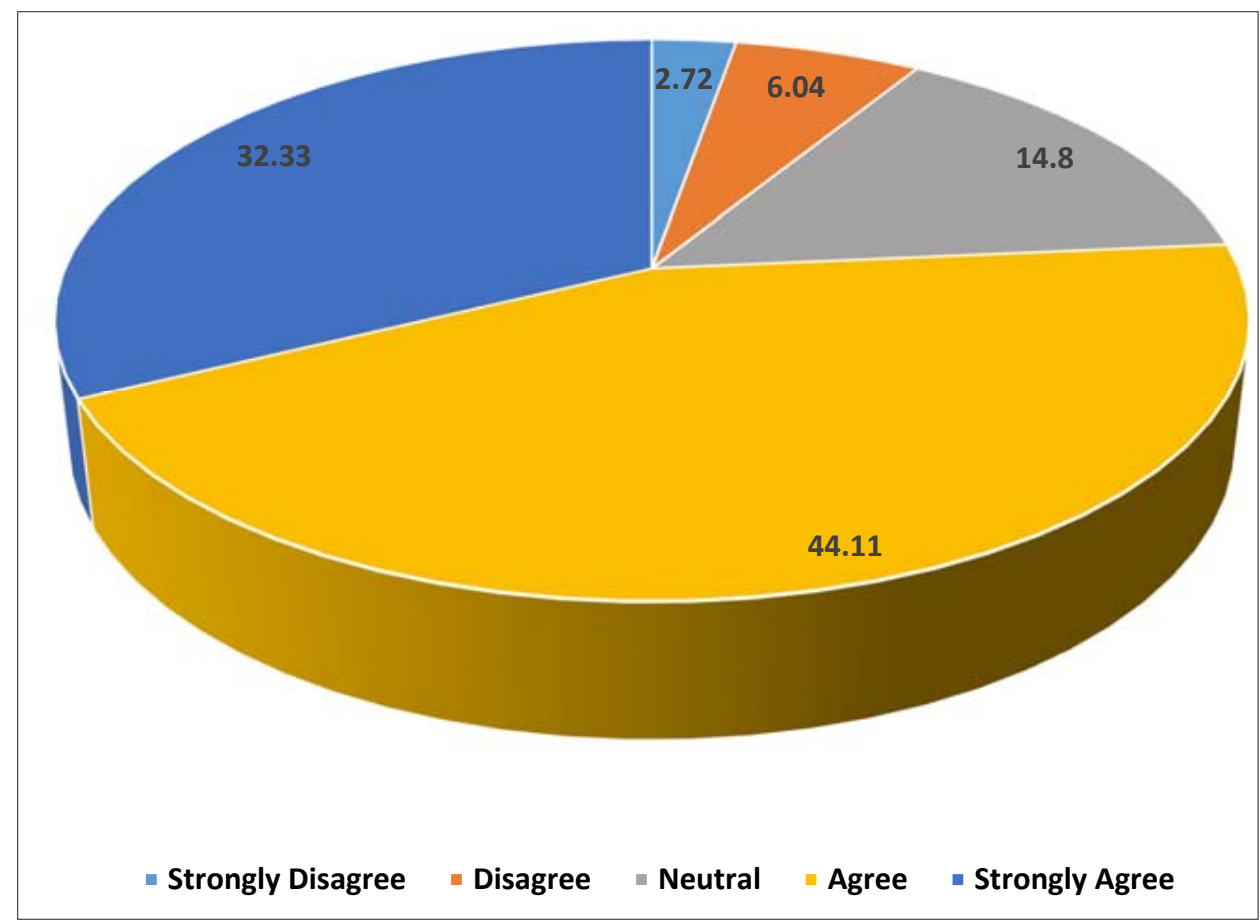

FIGURE 1: SOCIAL CAPITAL FOR ACCESSING SCHOLARSHIP OPPORTUNITIES

From Figure 1 it is clear that $32.33 \%$ and $44.11 \%$ of the respondents respectively strongly agreed and agreed that social media platforms are an important source of information for opportunities to fund their studies. This use of information as a social capital resource was also echoed by some of the participants in the focus groups. One of the participants said:

I always check my networks whether there are opportunities. I come from a poor background and even though I get NSFAS, it is not enough. I want to get additional support. If I can get a scholarship, I may also get a job after completing my studies. Many opportunities are shared on Facebook, Twitter and WhatsApp and we apply. Being on social networks and having many contact helps a lot.

Other participants said that for NSFAS (National Student Financial Aid Scheme), information on when to apply, and the requirements are often circulated on Facebook and WhatsApp. In other cases, social networks are important for enabling students to find work and voluntary opportunities, as well as understand job trends. Voluntary and work opportunities are important as they allow young people to gain work experience in order to secure employment. Even though the culture of voluntarism is not well established in South Africa, the results obtained in this study show that young people scan for a job and voluntary opportunities on social media. 


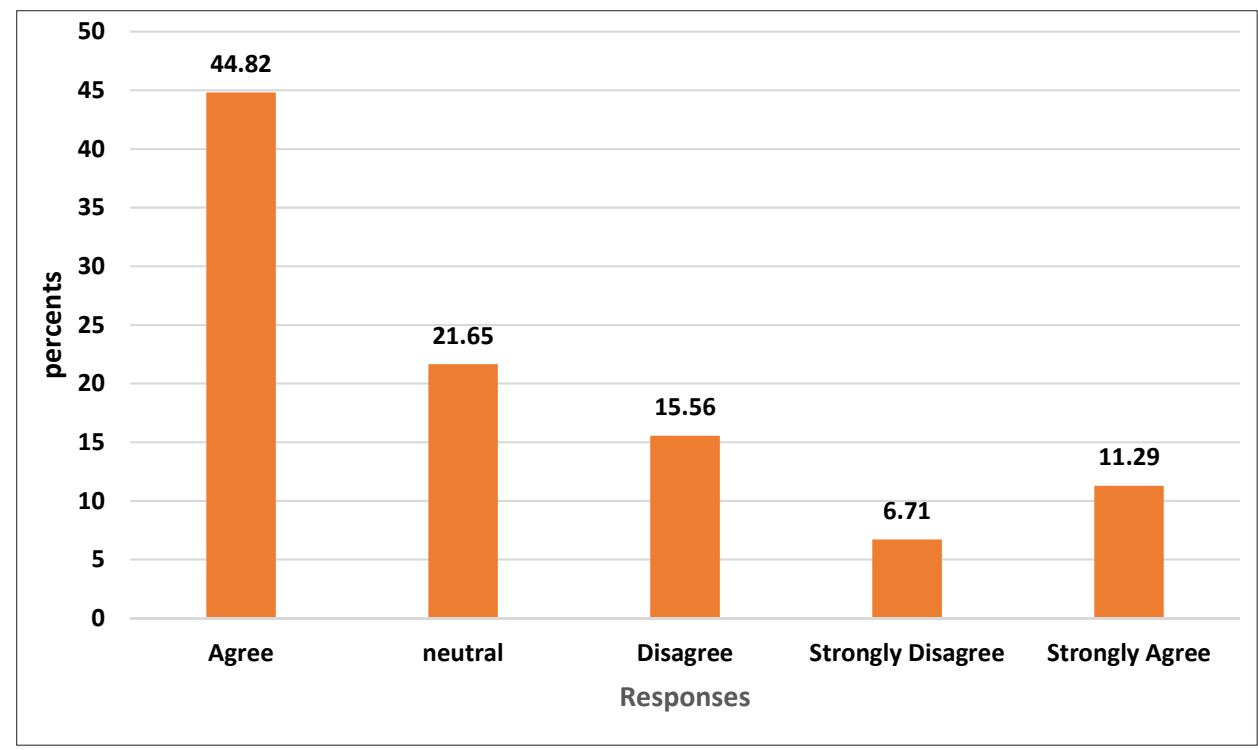

\section{FIGURE 2: USING SOCIAL MEDIA TO GET VOLUNTARY OPPORTUNITIES}

As seen in Figure 2 above, $44.82 \%$ of the respondents agreed with the statement, while another $11.29 \%$ strongly agreed. This means that over half of the respondents look to assist people voluntarily. Given the unemployment challenges faced by graduates, these results also show the necessity of encouraging students to start early to look for opportunities that will enable them to gain work experience. In the focus groups, some of the respondents noted that they have since stopped looking for these opportunities as some of the posts on Facebook and Twitter were merely for people to get followers. One of the respondents said:

For me I no longer check for these things on social media. On Twitter they always say DM me but when you do so there is no response. I now believe that people do that merely to get more followers and some of them are scams anyway. It is a waste of time. I will look for a job after finishing my studies.

Others acknowledged that, especially for campus jobs, they always find information on social networks:

The tutorship position I have, I saw it on social media. It was circulated on WhatsApp and I went to see my lecturer. Now I check for these opportunities always because I need to survive here on campus and also I need work experience.

These findings indicate that information availability and access is mediated by social networks and many young people are thus able to access information important for their growth and future professional lives. 


\section{Social media, altruism and social capital}

Social networks are also important sites for people who are experiencing difficult circumstances to ask for assistance from their social connections. On many social networks, people look for assistance, either in kind or for money. Crowd-funding platforms, such as gofundme.com, fundly.com, and doublethedonation.com, have social media accounts where they publicise appeals for help from individuals and organisations. For this study, when the participants were asked whether they think their online acquaintances will assist them, $74.44 \%$ of the respondents said that their connections will assist them.

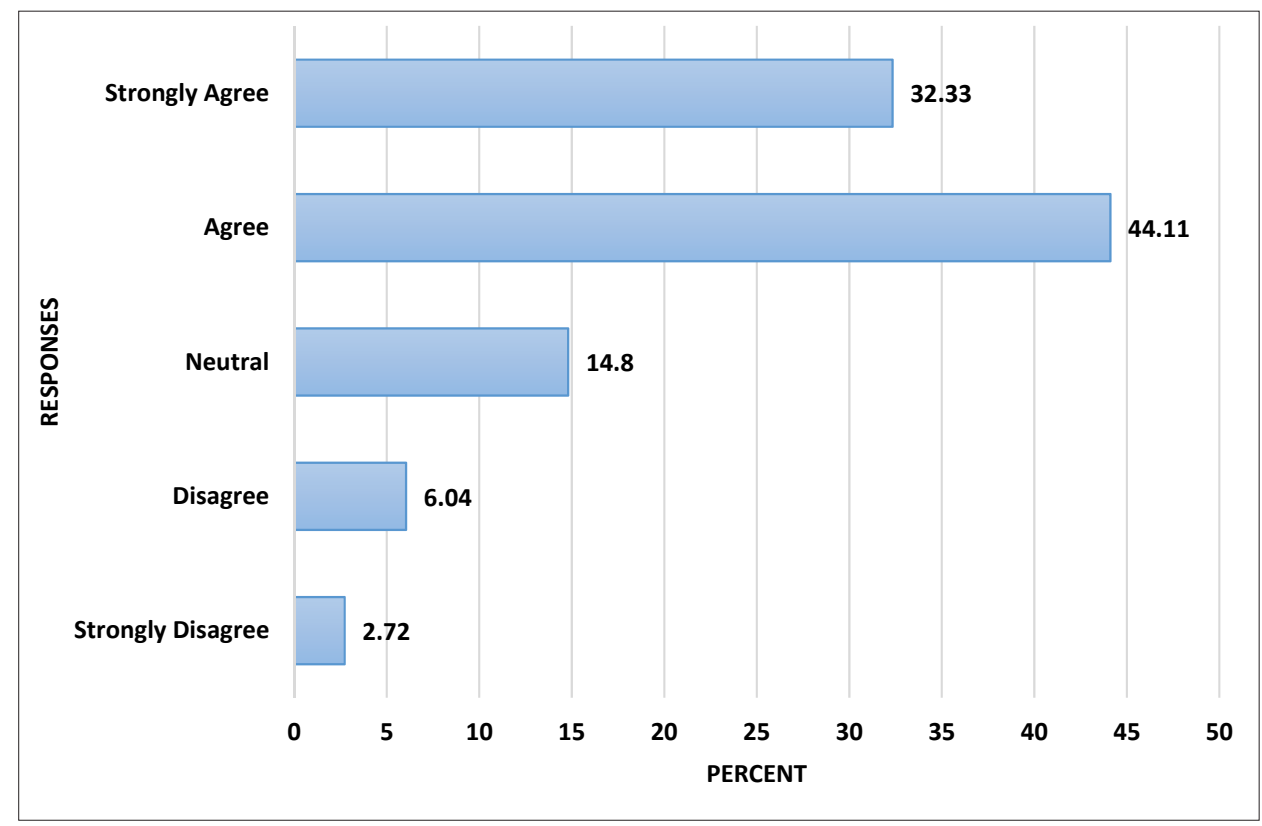

\section{FIGURE 3: SOCIAL ASSISTANCE AND COMFORT}

As shown in Figure 3, almost $41 \%$ of the respondents are either neutral or they do not view social media in that manner. These findings are in line with the observations by Ellison et al. (2014a), who stated that social media tools enable iterative communications, trust and intimacy, which enable others to help when the need arises.

The usefulness of social network connections was also echoed by a response from the focus group discussions. One of the high school participants said that when her teachers at her rural school realised about her financial challenges, they appealed on Facebook for assistance, and they managed to secure full tuition fees and accommodation. She said:

I think social media friends help a lot. If it was not that appeal on social media by my teachers, I would have dropped out of school. I know other people who have also been helped. Recently on Twitter someone wanted R10.00 of electricity and many people helped and they say, she got three years supply of electricity. 
The participants from the two tertiary institutions also supported these views, saying that people who go public about their circumstances are usually genuine. These findings confirm that social media tools are important sources of social capital, which can be activated and transformed into other forms of capital (Liu et al. 2016; Lin 1999).

\section{Social media use for entertainment and dating}

Young people also use social media for entertainment, dating and widening their social ties. Tong and Walther (2011) as well as Ellison et al. (2014a) observe that social media tools are use for nurturing, maintaining and initiating relationships, including dates. Many people also use social media for entertainment.

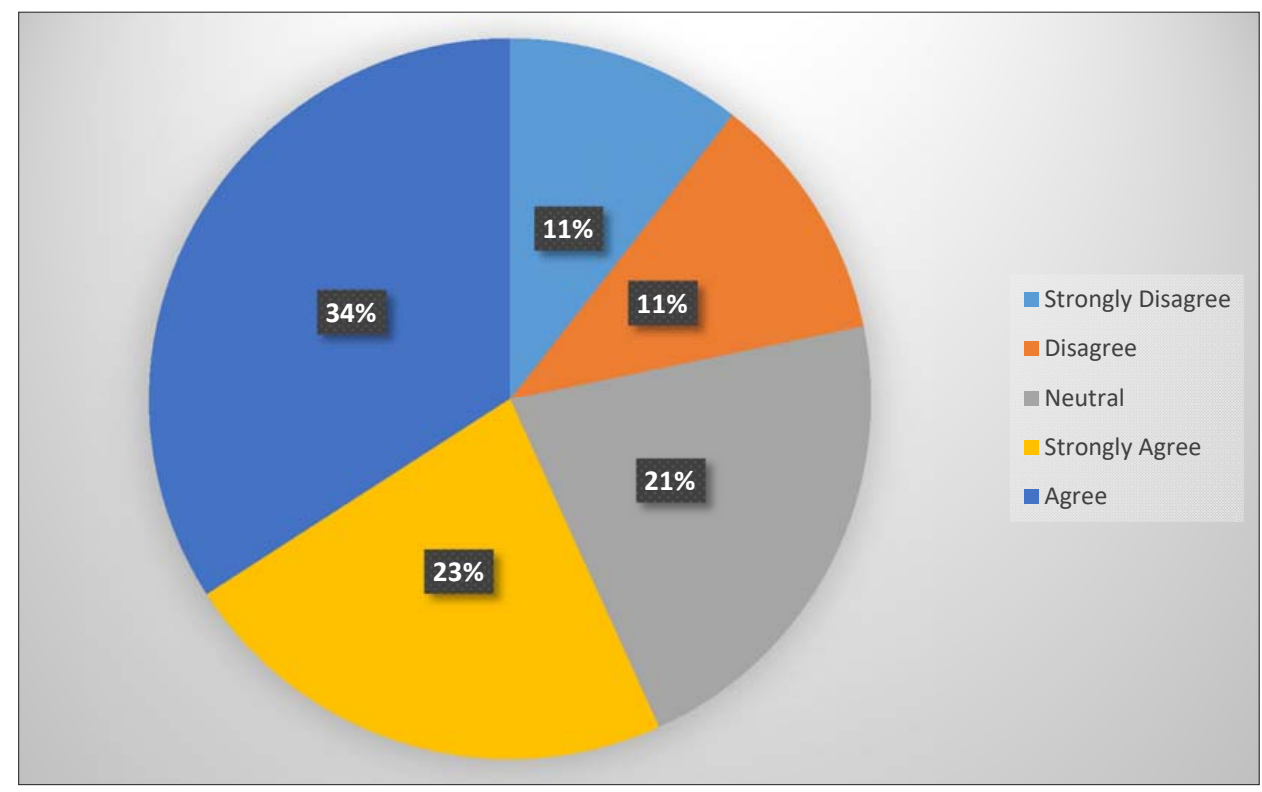

FIGURE 4: SOCIAL MEDIA FOR ENTERTAINMENT AND DATING

As shown in Figure 4, 22.66\% of the respondents strongly agree with the statement, while $34.14 \%$ agree. These results show that although young people prioritise entertainment, they use social networks for more productive purposes as well.

\section{CONCLUSION AND RECOMMENDATIONS}

Social capital is a necessity if societies are to ensure that youth involvement and development is attained. This study found that social network usage is an important way of cultivating social capital among young people. Through social media, young people are able to work together with their connections to achieve common good, as well as to attain individual well-being. In line with Presti's (2014) observations, social media applications enable young people to enhance their capabilities to achieve their own goals, such as education, social support and entertainment. This means that 
those with better capabilities of harnessing social capital online are in a better position to achieve personal and community development. From a policy perspective, this calls for society to prioritise digital literacy, which will enable young people to harness this digital capital.

In addition, this study highlights the agency of young people in determining what they use social media for and to what ends. They are indeed not human becomings (Leonard 2007) but human beings who use social media in specific ways to gain social capital. Unlike technological determinists, it has been concluded that young people use social media tools in their everyday self-activity, implying that young people's social acquisition processes must be derived from their own perspectives. It is important to develop policies that ensure inclusivity and break down those factors, which hinder young people from acquiring social capital, such as the digital divide, gender differences and others.

\section{REFERENCES}

Adler, S.P. \& Kwon, S. 2002. Social capital: Prospects for a new concept. Academy of Management Review 27(1): 17-40. https://doi.org/10.5465/amr.2002.5922314

Ahmad, K. \& Sheikh, S.K. 2013. Social media and youth participatory politics: a study of university students. Research Journal of South East Asia 28(2): 353-360.

Bennet, W.L. 2008. Changing citizenship in the digital age. [Online]. Available at: https:// pdfs.semanticscholar.org/efed/dd453b762b9f87e7da0e2ca724fbde5b9323.pdf [Accessed on 22 June 2017].

Bennet, W.L. \& Sergeberg, A. 2012. The logic of connective action: Digital media and the personalisation of contentious politics. [Online]. Available at: https://doi.org/10.108 0/1369118X.2012.670661 [Accessed on 20 May 2018]. https://doi.org/10.1080/136 9118X.2012.670661

Boeck, T.G. 2011. Young people and social capital: An exploration. [Online]. Available at: https://scholar.google.co.za/scholar?hl=en\&as_sdt=0\%2C5\&as_ vis $=1 \& q=$ Social + capital +and +young + people+Boeck $+\% 282011 \% 29 \& b \operatorname{bth}=$ [Accessed on 28 December 2019].

Boulienne, S. 2015. Social media use and participation: a meta-analysis of current research. Information, Communication and society 18: 524-538. https://doi.org/10.1080/1369 $118 X .2015 .1008542$

Bourdieu, P. 1985. The social space and the genesis of groups. Theory and Society 14(6): 723-744. https://doi.org/10.1007/BF00174048

Boyd, D.M. \& Ellisson, N.B. 2008. Social network sites: Definition, history, and scholarship. Journal of Computer-Mediated Communication 13(2): 516-529.

Burt, R.S. 1992. Structural holes. Cambridge, MA: Harvard University Press.

Castells, M. 2005. Global governance and global politics. Political Science and Politics 38(1): 9-16. https://doi.org/10.1017/S1049096505055678

Chawla, L. \& Malone, K. 2002. Neighbourhood quality in children's eyes. In: Christensen, P. \& O'Brien, M. (eds). Children in the city. London: Routledge-Falmer. 
Cresswell, J.W. \& Cresswell, J.D. 2018. Research design: Qualitative, quantitative, and mixed methods approaches. London: Sage.

De Zúñiga, H. \& Valenzuela, S. 2011. The mediating path to a stronger citizenship: Online and offline networks, weak ties, and civic engagement. Communication Research 38(3): 397-421. https://doi.org/10.1177/0093650210384984

Diof, M. 2003. Engaging postcolonial cultures: African youth public sphere. African Studies Review 46(2): 1-12. https://doi.org/10.2307/1514823

Ellison, B.N., Gray, R., Lampe, C. \& Fiore, T.A. 2014a. Social capital and resource requests on Facebook. New Media and Society 16(7): 1104-1121. https://doi. org/10.1177/1461444814543998

Ellison, N.B., Vitak, J., Gray, R. \& Lampe, C. 2014b. Cultivating social resources on social networks sites: Facebook relationship maintenance behaviours and their role in social capital processes, Journal of Computer Mediated Communication 19: 855870. https://doi.org/10.1111/jcc4.12078

Ferreira, J. \& Pantidi, N. 2018. Going digital: Integrating digital technologies in local community initiatives. [Online]. Available at: https://books.google.co.za/books?id= nd3kDAAAQBAJ\&pg=PA75\&lpg=PA75\&dq=Ferreira+and+pantidi\&source=bl\&ots =zPyrDwMIOr\&sig=ACfU3UOWkyNIUIUSTOVAOdzS5mS3kuBtFg\&hl=en\&sa= $X \& v e d=2 a h U K E w j H 18 K E o s b m A h U w S B U I H X 3 a C 3 M Q 6 A E w A n o E C A o Q A g \# v=$ onepage \&q=Ferreira\%20and\%20pantidi\&f=false [Accessed on 20 June 2019].

Fuchs, C. 2016. Critical theory. In: International Encyclopaedia of communication theory and philosophy. New Jersey: Wiley Blackwell. https://doi.org/10.1002/9781118766804. wbiect002

Ha, T., Han, S., Lee, S. \& Kim, H.J. 2016. Reciprocal nature of social capital in Facebook: An analysis of tagging activity. Online Information Review 41(6): 1468-4527. https:// doi.org/10.1108/OIR-02-2016-0042

Julien, C. 2015. Bourdieu, social capital and online interaction. Sociology 49(2): 356-373. https://doi.org/10.1177/0038038514535862

Kaplan, A.M. \& Heinlein, M. 2012. Social media: back to the roots and back to the future. Journal of Systems and Information Technology 14(2): 101-104. https://doi. org/10.1108/13287261211232126

Leonard, M. 2007. Children's citizenship education in politically sensitive societies. Childhood 14(4): 487-503. https://doi.org/10.1177/0907568207086411

Lin, N. 1999. Building a network theory of social capital. CONNECTIONS 22(1): 28-51.

Liu, D., Ainsworth, S.E. \& Baumeister, R.F. 2016. A meta-analysis social networks and online social capital. Review of General Psychology 20(4): 369-391. https://doi. org/10.1037/gpr0000091

Mandarano, L., Meenar, M. \& Steins, C. 2011. Building social capital in the digital age of civic engagement. Journal of Planning Literature 25(2): 123-135. https://doi. org/10.1177/0885412210394102

Munzel, A., Galan, J. \& Meyer-Waarden, L. 2008. Getting by or getting ahead on social networking sites? The role of social capital in happiness and well-being. International 
Journal of Electronic Commerce 22(2): 232-257. https://doi.org/10.1080/10864415 .2018.1441723

Norris, P. 2003. Social capital and ICTs: Widening or reinforcing social networks? Presented at the International Forum on Social Capital for Economic Revival, Japan, 24-25 March.

Papacharissi, Z. 2008. The virtual sphere 2.0: The Internet, the public sphere and beyond. In: Chadwick, A. \& Howard, P. (eds). Routledge Handbook of Internet Politics. London: Routledge.

Phua, J.J., Jin, S.A. \& Kim, J.H. 2017. Gratifications of using Facebook, Twitter, Instagram, or Snapchat to follow brands. Telematics \& Informatics 34(1): 412-424. https://doi. org/10.1016/j.tele.2016.06.004

Portes, A. 1998. Social capital: Its origins and applications in modern sociology. Annual Review in Sociology 24: 1-24. https://doi.org/10.1146/annurev.soc.24.1.1

Presti, L.V. 2014. Digital capabilities and social capital. European Journal of Research on Education 7: 12-17.

Putnam, R.D. 2002. Bowling together: The united state of America. The American Prospect 13: $20-22$.

Steenkamp, M. \& Hyde-Clarke, N. 2014. The use of Facebook for political commentary. Telematics \& Informatics 31: 91-97. https://doi.org/10.1016/j.tele.2012.10.002

Theocharis, Y. 2015. The conceptualisation of digitally networked participation. Social Media + Society 1(2): 1-14. https://doi.org/10.1177/2056305115610140

Tong, S. \& Walther, B.J. 2011. Relational maintenance and CMC. [Online]. Available at: https://www.researchgate.net/publication/281317578_Relational_maintenance_ and_CMC/link/56277ace08aefb81befbaaa5/download [Accessed on 26 December 2019].

Van Deth, W.J. 2009. New modes of participation and norms of citizenship. [Online]. Available at: https://www.academia.edu/2233375/New_Modes_of_Participation_ and_Norms_of_Citizenship [Accessed on 20 May 2017].

Zhang, X. \& Lin, W. 2018. Stoking the fires of participation: Extending the Gamson Hypothesis on social media use and elite-challenging political engagement. Computers in Human Behaviour 79: 217-226. https://doi.org/10.1016/j.chb.2017.10.036 